\title{
Linagliptin, when compared to placebo, improves CD34+ve Endothelial Progenitor Cells in Type 2 diabetes subjects with chronic kidney disease taking metformin and/or insulin, a randomized controlled trial.
}

\section{Hassan B Awal}

George Washington University

Seshagiri Rao Nandula

George Washington University

\section{Cleyton C Domingues}

George Washington University

\section{Fiona J Dore}

George Washington University

Nabanita Kundu

George Washington University

\section{Beda Brichacek}

George Washington University Mona Fakhri

George Washington University

\section{Adrian Elzarki}

George Washington University

Neeki Ahmadi

George Washington University

\section{Shauna Safai}

George Washington University

\section{Magan Fosso}

George Washington University

Richard L. Amdur

George Washington University

\section{Sabyasachi Sen ( $\nabla$ ssen1@gwu.edu )}

George Washington University https://orcid.org/0000-0002-3675-9129 
Keywords: linagliptin, EPC, endothelium, CD34+, Type 2 Diabetes, diabetic kidney disease

Posted Date: March 30th, 2020

DOI: https://doi.org/10.21203/rs.3.rs-18330/v1

License: (c) (1) This work is licensed under a Creative Commons Attribution 4.0 International License. Read Full License

Version of Record: A version of this preprint was published at Cardiovascular Diabetology on June 3rd, 2020. See the published version at https://doi.org/10.1186/s12933-020-01046-z. 


\section{Abstract}

Introduction: Endothelial Progenitor cells (EPCs) has been shown to be dysfunctional in both Type 2 Diabetes and Chronic Kidney Disease (CKD) leading to poor regeneration of endothelium and renal perfusion. EPCs have been shown to be a robust cardiovascular disease (CVD) risk indicator. Cellular mechanisms of DPP4 inhibitors such as Linagliptin (LG) on CVD risk, in patients with Type 2 Diabetes with established CKD has notbeen established.

Hypothesis : Linagliptin, a DPP4 inhibitor when added to insulin, metformin or both may improve endothelial dysfunction in a diabetic kidney disease (DKD) population.

Methods : 31 subjects taking metformin and/or Insulin were enrolled in this 12 weeks, double blind, randomized placebo matched trial, with $5 \mathrm{mg} \mathrm{LG}$ compared to placebo. Type 2 diabetes subjects (30-70 years old), HbA1c of $6.5-10 \%$, CKD Stage 1-3 were included. CD34+ cell number, migratory function, gene expression along with vascular parameters such as Arterial stiffness, biochemistry, resting energy expenditure and body composition were measured. Data were collected at week 0,6 and 12. A mixed model regression analysis was done with $p$ value $<0.05$ considered significant.

Results : A double positive CD34/CD184 cell count had a statistically significant increase $(p<0.02)$ as determined by flow cytometry in LG group where CD184 is SDF1a cell surface receptor. Though mRNA differences in CD34+ve was more pronounced CD34- cell mRNA analysis showed increase in antioxidants (SOD2, Catalase and CPX) and prominent endothelial markers (PECAM1, VEGF-A, vWF and NOS3). Arterial stiffness measures such as augmentation Index (AI) $(p<0.04)$ and pulse wave analysis (PWV) were improved (reduced in stiffness) in LG group. A reduction in LDL: HDL ratio was noted in treatment group $(p<0.04)$. Urinary exosome protein examining podocyte health (Podocalxyin, Wilms tumor and Nephrin) showed reduction or improvement.

Conclusions : In DKD subjects, Linagliptin promotes an increase in CXCR4 expression on CD34+ progenitor cells with a concomitant improvement in vascular and renal parameters at 12 weeks

\subsection{Background}

Over 1 in 10 Americans are suffering from Type 2 Diabetes, which in recent times has risen to a national epidemic $(1,2)$. Diabetes and chronic kidney disease (CKD) are conditions that are responsible for vascular damage and complications, both micro and macrovascular, including endothelial dysfunction, endothelial cell inflammation, oxidative stress, and cardiovascular pro-thrombotic states (3-5). Endothelial progenitor cells (EPCS, defined here as CD34 + cells) are specialized stem cells responsible for repair of the endothelial cell lining of blood vessels and angiogenesis. These cells can be harvested from peripheral whole blood derived mononuclear cells (MNC) by positive sorting for CD34 peripheral cell surface receptor. It has been shown that high glucose environment, as seen in diabetes mellitus (either type 1 or 2), leads to functional impairment of circulating EPCs. Their number goes down, along with their 
ability to form colonies and migration to the site of endothelial damage (6-10). Other studies have shown that healthy CD34 + cells can effectively repair damaged endothelial cell lining (11) .

We currently use serum based biochemical parameters for estimation of cardiovascular disease (CVD) risk, which might take several weeks or even months(12) to change as they are paracrine properties of a particular cell lines that is injured or damaged, such as hs-CRP, a factor produced from inflamed endothelium. Based on literature and our past CD34 + ve cell based studies, it is likely that circulating CD34 + EPC number, function and mRNA expression can act as a robust cellular biomarker that is more reliable than serum-based biomarkers for monitoring endothelial dysfunction in Type 2 Diabetes(13-17) .

Dipeptidyl peptidase-4 (DPP-4) enzyme inhibitors, are a class of oral anti-diabetic medications, that have been shown to achieve improved glycemic control by lowering $\mathrm{HbA1C}$, without causing hypoglycemia, and are weight neutral(18). DPP-4 enzyme degrades incretins such as GLP1 and GIP, including chemotactic factors such as SDF-1区 (stromal derived factor). Therefore, use of DPP4 inhibitor is expected to be associated with increased bioavailability of SDF1a. This may help "homing-in" of CD34 + endothelial progenitor cells to the damaged endothelial sites (that are producing SDF1a) thereby help endothelial regeneration. This can be a potential mechanism to prevent endothelial damage which may translate to vascular damage repair through-out the body. However, there is limited data demonstrating the potential cardiovascular effect of these medications. A few studies using either Sitagliptin or Saxagliptin have shown an increase in endothelial progenitor cells, and thus potential cardiovascular benefits, with DPP-4 therapy is possible $(13,14,19)$. Literature has shown that DPP-4 inhibitors may increase EPC mobilization from the bone marrow by increasing SDF-1 a in the plasma $(13,20)$. The upregulation of SDF1a and also VEGF in the plasma increase mobilization and recruitment of EPCs to the site of the ischemic injury for repair and regeneration(21-24).

As mentioned before chronic kidney disease (CKD) is a CVD equivalent risk factor independent of diabetes. It is unknown whether Linagliptin, a DPP-4 inhibitor, will have any positive effect on human EPC function with two prominent cardiovascular risk factors co-existing such as CKD and Type 2 Diabetes. In this 12-week placebo-matched clinical trial, we studied the effect of Linagliptin. Linagliptin was added to metformin and/or Insulin, in subjects with Type 2 Diabetes and Stage I-III Chronic Kidney Disease but without any established adverse cardiovascular event (such as history of myocardial infarction or cerebral stroke).

\subsection{Methods}

\subsection{Trial Design and Oversight}

This is a phase 4 (post-marketing), two arm, single site, parallel group, double blind, placebo controlled randomized clinical trial comparing Linagliptin $5 \mathrm{mg}$ tablets, taken orally, once daily, with matching placebo. The study was conducted in accordance with Good Clinical Practice guidelines set forth by the International Conference of harmonization and any local regulatory guidelines with the approval and oversight of the George Washington University Institutional Review Board. The trial was funded by 
Boehringer Ingelheim and conducted by the Investigator-Sponsor Dr Sabyasachi Sen at the George Washington University.

Subjects were initially pre-screened to assess eligibility. Once determined preliminary eligibility, they were brought in for a screening visit to confirm eligibility via interview, medical record check and laboratory workup once the subject signed the informed consent. The subjects were then enrolled into one of two arms of the study: $5 \mathrm{mg}$ Linagliptin or matching placebo.

17 subjects were enrolled into the active group and 14 subjects were enrolled into the placebo group.

There were 3 study visits total, first at week 0 , second at week 6 and third at week 12 . All three of the visits had same assessments. The assessments that were done were: vital measurements, adverse event (AE) check and a peripheral blood draw. Approximately $80 \mathrm{ml}$ of blood was drawn for CD34+ endothelial progenitor cell harvesting and routine blood work.

Other parameters tested were resting metabolic rate (RMR, energy expenditure), measurement of waist to hip ratio, urine sample collection, Tanita body composition scale, pulse wave analysis and pulse wave velocity to determine arterial stiffness. Subjects were advised to adhere to 150 minutes of weekly aerobic exercise and their activity levels were monitored using ACTi graph activity monitor.

A follow up phone call visit was done 30 days from the last in-person visit to assess for any residual adverse events (AE).

\subsection{Participants}

Subjects were included if they were between 30 to 70 years old inclusive, with a diagnosis of Type 2 Diabetes for 15 years or less. Glycated hemoglobin level (HbA1c) inclusions were between 6.5 to $10.0 \%$ Inclusive. Their baseline medications were stable dose of Insulin (either short acting or long acting) and/or Metformin (1-2 grams per day). A stable dose was considered to be at least the maximum labeled dose or dose not associated with unacceptable side effects. Patients with BMI between 25 and 39.9 $\mathrm{kg} / \mathrm{m} 2$ were included, thereby excluding severe obesity. Only, patients with impaired renal function were included, with Chronic Kidney Disease stage 1 to 3, defined as estimated minimum GFR of 30 $\mathrm{ml} / \mathrm{min} / 1.73$ (GFR, as calculated by MDRD formula).

Any patients with Type I diabetes, history of Diabetic ketoacidosis, low hematocrit (less than 28 units), history of recent pancreatitis or cancer, recent coronary or cerebrovascular event within 6 months, use of consistent steroid medications, untreated thyroid disease was excluded.

Additional Inclusion and Exclusion criteria can be found in Appendix 1.

\subsection{Outcome Objectives}

The Primary objective is to ascertain if addition of Linagliptin improves CD34+ cell number, (CD34+ number, \%CD34+ of total Mononuclear Cell population) function (cell migration function in response to 
SDF1a) and gene expression, in early Type 2 Diabetes Mellitus with CKD Stages 1-3, which will be correlated to improvement in 24 hour urinary protein estimation and serum Creatinine Clearance.

The secondary objective is to correlate the cellular outcome measures with other measures of endothelial function such as Arterial Stiffness (measured by Pulse Wave Analysis [Augmentation Index] and Pulse Wave Velocity [m/s]), Serum Biochemistry (CMP, IL6, hsCRP, Leptin, Serum insulin, TNFa), Adiposity (as \% body fat), Resting Energy Expenditure (in kcal) and Glycemic control (through $\mathrm{HbA} 1 \mathrm{c}$ ).

\subsection{Cellular and Clinical Assessments}

2.41 CD34+ Endothelial Progenitor Cell Analysis: Peripheral blood samples (approximately $60 \mathrm{ml}$ ) were drawn from patients and phosphate buffered saline (1:1) was added. Mononuclear cells (MNCs) were then isolated from whole blood using a Ficoll density centrifuge method. MNCs were counted and aliquot was used for CFU-Hill colony formation assay following the manufacturer's instruction (Stem Cell Technologies, Vancouver, BC, Canada). Colony forming unit was counted at day14. A fraction of the MNC were stained with (FITC, PE, APC) conjugated antibodies (Miltenyi Biotec GmbH, Bergisch-Gladback, Germany) in order to analyze specific progenitor cell surface marker (CD34) and mature endothelial cell surface markers (CD31) or receptor for SDF1a ligand, CXCR4) by flow cytometry.

To isolate EPCs (CD34+), MNCs were magnetically sorted through a column after cells were stained with CD34+microbeads antibody (Miltenyi Biotec GmbH, Bergisch Gladback, Germany). An aliquot of CD34+ cells were then stained with trypan blue and counted using an Auto Cellometer Mini (Nexcelom Bioscience, Lawrence, MA) to assess viability.

CD34+ gene expression analysis was performed by quantitative reverse transcriptase polymerase chain reaction (qRT-PCR). CD34 +ve cell total mRNA was extracted and purified using the RNeasy Minikit (Qiagen). mRNA was then converted into cDNA by using the high capacity cDNA reverse transcriptase kit (Applied Biosystems) Possible gene expression changes promoted by Linagliptin was assessed by a CFX96 real-time PCR systems (Bio-Rad) using Taqman Universal masters Mix II (Applied Biosystems) and inventoried probes. The gene expression analysis included antioxidants, apoptosis, endothelial functions, chemotaxis, inflammation and endothelial lineage cell surface markers. The expression of each individual gene was normalized to either housekeeping $18 \mathrm{~S}$ or GAPDH and calculated using C-ddct method considering the difference in cycle threshold between visit 2 and 3 and baseline (Visit 1). mRNA gene expression of CD34- cell population (from MNC population) was also analyzed along with CD34+ cells.

The migratory capacity of CD34+ was evaluated using the CytoSelect 24-well Cell Migration Assay kit (Cell Biolads, Inc., San Diego, CA). Cells were suspended in Serum free media and seeded at 100,000 cells per insert. Migration of the cells through a 3 um polycarbonate membrane to the wells containing a serum-free media (control) and chemoattractant SDF-1a (10 or $100 \mathrm{ng} / \mathrm{mL}$ ) was assessed after cells were kept overnight in incubator. Migratory cells were dissociated from the membrane and subsequently lysed and quantified by fluorescence $(480 \mathrm{~nm} / 530 \mathrm{~nm}$ ) using CyQuant GR dye (Cells Biolabs, Inc, San Diego, 
CA). The fluorescence ratios between cells exposed to the chemotactic factor and cells exposed to chemoattractant-free media (control) along the visits were used to analyze the migratory capacity of the cells)

As is the case with diabetic patients, number of isolated CD34+ cells is usually not as high as anticipated due to established endothelial damage and because the progenitor cells are very susceptible to apoptotic death in hyperglycemia. Hence in order to understand some of the effect of protein upregulation we have done the analysis on all remaining CD34- cells as they are the remaining $99 \%$ of Polymorphonuclear cells. Idea is that any gene expression upregulation on CD34+ cells should also be prevalent in CD34- cells and should by and large reflect the mRNA analysis of unsorted MNC population.

\subsection{Body Composition Measurement. Body composition was measuring using Tanita ${ }^{\mathrm{TM}} \mathrm{BF}-350$ Body} Composition Scale and manually. Manual measurement included height, waist circumference, hip circumference. Tanita scale uses a bio-impedance electrical impulse to measure body fat percent, fat mass $(\mathrm{kg})$, fat free mass $(\mathrm{kg})$, percent body water, water mass $(\mathrm{kg})$ alongside weight. It then calculates the $\mathrm{BMI}$ and estimated basal metabolic rate.

2.43 Basal Metabolic Rate Measurement. Resting Emergency Expenditure (REE) was measured using KORR REEVUE. Test was conducted with the subject sitting and well rested. Subject was instructed to keep a tight seal around the mouthpiece and use the nose clip to avoid breathing in from the nose. The test ran for about 10 mins. It calculated estimated REE, predicted REE, estimated TEE (Total Energy Expenditure), VO2 Max and estimated calorie intake per day.

2.44 Arterial Stiffness: This parameter was measured using AtCor SphygmoCor CP system. We obtained two outcomes such as: Pulse Wave Velocity and Pulse Wave Analysis. The patient was supine on the examination table, 3 leads were attached on right forearm, left forearm and left shin.

Pulse Wave Analysis (PWA) was measured on the left Radial Artery with the subject supine. At least three readings were taken with Operator Index $\geq 80$. Measurement includes Augmentation Index (Al), Augmentation Index adjusted for Heart Rate of 75 (Al-75), Augmentation Pressure (AP), Aortic and Radial reading of systolic, diastolic, pulse pressure and mean pressure.

Pulse Wave Velocity (PWV) was measured with the subject supine. This measurement requires a distal and proximal artery. Distal was used as right femoral artery with proximal being the left carotid. Index and ring fingers were used to manually localize the pulse, sometimes an arterial Doppler was used to localize the femoral pulse on patient with challenging body habitus. Once a stable pulse waveform was observed, the probe position was kept stable for 20 more pulses before the reading was finalized. Three readings were taken with standard deviation of less than $10 \%$. The result reported a velocity in $\mathrm{m} / \mathrm{s}$, alongside the standard deviation with error.

2.45 Biological Sample and Vital Collection: A venous blood sample was collected from the Antecubital fossa. About $80 \mathrm{ml}$ of blood was collected. $60 \mathrm{ml}$ for EPC analysis and $20 \mathrm{ml}$ for standard of care blood 
works which included Basic Metabolic Panel, Lipid Panel, HbA1c, hsCRP, IL6, Adiponectin and Insulin. ELISA was performed to analyze serum GLP1 and SDF1 a using ELISA Immunoassay kit (Raybiotech, Norcross, GA) for GLP1 and Sandwich ELISA (EHCXCL12A, Thermo Scientific) for SDF1a. Urine sample was collected for urine Microalbumin and Creatinine ratio. Vitals were gathered on the left arm, Systolic Pressure, Diastolic Pressure and heart Rate, along with sublingual temperature.

2.46 ACTi graph Activity Monitor. Subjects level of activity was measured using Actigraph wGT3x-BT activity monitors. Subjects was advised on diet and exercise instructed to wear the meter during all waking hours and was advised to adhere to $150 \mathrm{~min}$ of moderate intensity aerobic exercise per week. Actigraph served as a measure of this exercise compliance, and to verify for exercise as a confounding variable.

\subsection{Polyethylene Glycol (PEG) enrichment of Extracellular vesicles:}

The cells debris and large apoptotic bodies were removed from the urine samples by centrifugation at $500 \mathrm{~g}$ for 5 minutes followed by $3000 \mathrm{~g}$ for 30 minutes at $4^{0} \mathrm{C}$. Transfer supernatant into ultracentrifugation tubes and centrifuged at $100,000 \mathrm{~g}$ at $4^{0} \mathrm{C}$ for $75 \mathrm{~min}$ (Optimal XPN-100 centrifuge, Beckmann Coulter Inc, US). After ultracentrifugation the pellet was dissolved in RIPA buffer with protease inhibitor cocktail and stored the sample at $-80^{\circ} \mathrm{C}$ for further analysis.

Western blotting: Extracellular vesicle extracts were fractionated by SDS-PAGE and transferred to a polyvinylidene difluoride membrane using a transfer apparatus according to the manufacturer's protocols (Bio-Rad). After incubation with 5\% nonfat milk in TBST (10 mM Tris, pH 8.0, $150 \mathrm{mM} \mathrm{NaCl}, 0.5 \%$ Tween 20) for $60 \mathrm{~min}$. The membrane was washed once with TBST and incubated with antibodies against CD9 (1:1000), CD81 (1:1000), CD63 (1:1000), HSP70 (1:1000), anti-podocalyxin (PODXL, 1:1000), anti- wilms tumor protein (1:1000) and anti-Nephrin antibody $(1: 1000)$ at $4{ }^{\circ} \mathrm{C}$ for $12 \mathrm{~h}$. Membranes were washed three times for $10 \mathrm{~min}$ and incubated with a 1:20000 dilution of horseradish peroxidase-conjugated goat anti-rabbit antibody for $90 \mathrm{~min}$ at room temperature. Blots were washed with TBST three times and developed with Pierce ECL kit (ThemoFisher Scientific, USA).

\subsection{Statistical Analysis}

Continuous variable distributions were examined using histograms for skewness or outliers. When these were present, we did not use parametric statistics for these variables. For normal variables, we used 2tailed between-groups t-tests to examine differences between treatment groups at baseline on continuous variables, and either chi-square or the Fishers Exact test for categorical variables. To examine differences between treatment groups across all time points, as well as time effects, and whether the slope of change over time differed between treatments, we used random effects mixed model regression, examining the main effects of treatment (Linagliptin vs placebo), and time (v1, v2, v3), and the treatment by time interaction. This method allows us to use all non-missing subject data and adjusts for within-subject auto-correlation. For variables with significant effects in the mixed models, we examined the means graphically. For skewed variables or those with outliers, we used the Kruskal-Wallis test to examine 
differences in the distribution location (i.e. median) within time points, across treatment groups. SAS (version 9.4, Cary, NC) was used for data analysis with $p<.05$ considered significant.

Since subjects were randomized to treatment, chance of baseline subject characterizations acting as confounders are minimized. Therefore, randomized control trials do not usually adjust for baseline differences. In gene expression variables, outliers with expression values $>50$ were dropped, and values were natural log transformed due to skewness [using log (expression +1)]. Expression values that still had outliers after log transformation were capped at value of 2 .

\subsection{Results}

\subsection{Primary Outcome}

Characterization of endothelial progenitor cells (CD34+ve): To find out the effect of DPP4 inhibitor, linagliptin, on the endothelial progenitor cell number, we counted the total CD34+ cell number in both placebo and linagliptin groups. The flowcytometric analysis of the cell numbers as shown in the Figure 1A, the number of cells purified from MNCs did not show any significant difference between the groups, at visit 3, however, the CD34+ cell number increased from visit 1 to 3 in linagliptin group. Mean CD34+ CD184+ double positive cells increased from visit 1 to 2 in linagliptin group as compared to the placebo group. (Figure 1B).

The migratory response of CD34+ cells to the chemotactic factor SDF1a $(100 \mathrm{ng} / \mathrm{ml} \mathrm{I})$ was not statistically significant between the groups. However, the migratory response to $100 \mathrm{ng} / \mathrm{ml}$ of SDF1a showed a trend in increase in the linagliptin group starting at visit 2 (Figure 1C). That is there was a steep rise in migration of CD34+ve cells in response to SDF1a between visit 2 and 3 , in the linagliptin group.

\subsection{Gene Expression Analysis}

The effect of linagliptin on the gene expression of CD34 negative cells

Gene expression analysis was performed for antioxidants (SOD2, GPX1, CAT), endothelial function (VEGFA, PECAM1, eNOS) and endothelial cell lineage surface marker. Due to insufficient mRNA isolation from low number of CD34+ cells, gene expression analysis was not helpful. We also looked at CD34-ve cells which is expected to be similar to unsorted MNC population. The gene expression analysis by qPCR for endothelial markers PECAM1, VEGF-A and VWF has increased 11 fold, 5 fold and 5 fold simultaneously in the linagliptin group in visit3 (Figure 2A). A two fold upregulation of these genes in visit 2 is also been observed (data not shown). Since the endothelial gene expression is increased significantly, we were interested to see the expression of endothelial functional genes vWF and NOS3(or 
endothelial nitric oxide synthase, eNOS). Both were upregulated by 5 fold and 2 fold in linagliptin group in visit 3 (Figure.3).

Later we have also analyzed the mRNA expression of antioxidant genes that are known to play a key role in cellular redox balance, such as superoxide dismutase 2 (SOD2), catalase (CAT) and glutathione peroxide 1 (GPX-1). Again we have observed a marked increase in expression of these genes in linagliptin group in visit 3 as shown in Figure 2B.

\subsection{Urinary Function Marker}

\subsection{Quantification of exosomal proteins in urine samples by western blot:}

Recently urinary exosomes are being used as biomarker for kidney diseases. We were interested to study urinary exosomal expression for Nephrin, renal Wilm's Tumor (WT-1) and podocalyxin like protein 1( PODXL) in urine samples from placebo and linagliptin group. As shown in the Figure 3 , the band intensities for the PODXL and WT-1 were high in visit 1 in linagliptin group as compared to placebo group. Whereas, there is no difference in band intensities for the PODXL and WT-1 proteins in Visit 2 and 3 between the groups. Nephrin expression was not different between the groups in visit 1 and 2 where as in visit 3 the placebo group has shown more Nephrin band intensity as compared to linagliptin group.

There no significant change in the eGFR and Serum Creatinine between the two groups however interesting pattern can be appreciated when one plots the change in urine Microalbumin over creatinine ratio (Figure 4). At baseline the linagliptin group had higher urine proteinuria and that remained stable from visit 1 to visit 2 . From visit 2, proteinuria started to drop in both groups, but the reduction gradient was more acute and obvious in the linagliptin group.

\subsection{Secondary Objective Measures}

\subsection{Venous Blood Biochemistries:}

Venous blood biochemistries were gathered, both through Labcorp of America and through serum ELISA and both standard of care and research labs were collected.

Detailed lab values of selected significant parameter are on table 2 . We found statistically significant difference in the LDL over HDL ratio $(p<0.04)$. The strongest effect of all the variable is the effect on time on HbA1c $(p<0.005)$, which means HbA1c went down substantially in both the treatment and control group (Figure 5). Even though the effect of treatment on this variable was not significant after the effect of time was accounted for, interesting trend pattern can be appreciated when it's graphed. The Hba $1 \mathrm{c}$ is relatively stable in the placebo group but has a clear downward trend in the treatment group.

\subsection{Arterial Stiffness:}

Stiffness of an artery significantly contributes to lack of pliability and contractility and is an important marker of increased peripheral resistance, diastolic dysfunction and systemic hypertension. It is 
associated with cardiovascular diseases in older individuals and is positively associated with hypertension, Coronary Artery Disease, stroke, heart failure and atrial fibrillation(30,31). Arterial stiffness is assessed using parameters such as augmentation index (Al) adjusted for a heart rate of 75 (Al-75) and Pulse Wave Velocity (PWV).

For PWV (Figure 6A), At Visit 1, the Linagliptin group demonstrated lower PWV at a trend level of significance $(p=.06)$. At visit 2 , surprisingly there was no difference $(p=.91)$, however at visit 3 , or at the end of the study, the Linagliptin group had significantly lower PWV $(p=.03)$, compared to placebo group. The Linagliptin group showed significant decrease from visit 2 to 3 , compared to the placebo group. No statistically significant changes in systolic blood pressure was noted between the groups.

Al-75 was found to be statistically significant along with augmentation pressure (AP) (Figure 6B). There was no significant effect of treatment group $(p=.07)$, or of time $(p=.98)$, but there was a significant group $x$ time interaction $(p=.02)$. The Linagliptin group increased more than placebo group from visit 1 to visit 2 , but then reversed back down more than the control group at visit 3 .

\subsection{Adiposity:}

Body composition measurement showed no statistically significant change amongst the group throughout the visits. As expected, given short duration of the treatment the subjects were asked to maintain activity level as advised by ADA for healthy living. There was no statistically significant change in hip to waist ratio, body weight and body fat percent amongst the treatment and control group. As we know from prior study that physical activity, even for a short duration, can improve endothelial function and CD34+ circulating progenitor cells in patients with endothelial dysfunction(32) .

\subsection{Resting Metabolic Rate}

Interestingly there was a large baseline difference in Basal Metabolic Rate amongst the treatment $1868 \pm$ 293 and control group (1476 \pm 448$)$ but the change between the groups in this parameter was not clinically significant $(p<0.87)$.

\subsection{Discussion}

\section{Primary Outcome: Cellular}

In this study we investigated the effect of DPP4 inhibitor linagliptin in addition to metformin and/or Insulin on CD34+ EPCs and CD34+ CD184+ cells as a marker for vascular endothelial function. CD184 is the marker for SDF1a receptor. We also monitored gene expression of CD34 negative cells. The latter will be reflective of a population similar to mononuclear cells (MNC) and can give indication of general health of hematopoietic cells. The subjects recruited in this study had type 2 diabetes mellitus (T2DM) and have established chronic kidney disease (CKD), similar to, established cardiovascular disease. As discussed in our previous study on saxagliptin, we used CD34+ cells as marker to identify EPCs (33). Here we have shown that, treatment with linagliptin significantly increased $(p=0.02)$ the CD34+ EPC number as 
compared to placebo group. Similarly, CD34+ CD184+ve cells were increased significantly from visit one to visit two and then show a persistence in trend showing increase from visit 2 to 3 . Taken together our observation of an increase in CD34+ EPCs and CD34+CD184+ cells (Figure 1) in linagliptin group are similar to the results from a recent study looking into the effects of linagliptin alone on EPCs in T2DM subjects (20) It has been reported that CD34+ cells from patient with T2DM have impaired chemotaxis response to SDF1 a resulting in reduced vasculogenic potential(24,34) In addition, the increase in CXCR4 (CD184+) expression is correlated with the increased migratory response to SDF1-a of CD34+ cells in linagliptin group (Figure 1C).

In order to understand the genotypic effect of linagliptin and metformin on gene expression we did qPCR analysis on CD34 negative cells. These cells are primarily hematopoietic cells. Here, we observed significant increase in antioxidants (SOD2, catalase and GPX1) in linagliptin group as compared to placebo (Figure 2B). In support of this we also found significant increase in the endothelial markers and functional genes (PECAM1, VEGF-A and VWF and NOS3) in linagliptin group as compared to placebo group (Figure 2A). These observations are in agreement with our previous published results suggesting patho-physiological role of ROS activation and therapeutic reduction in CD34+ve cells in diabetes (33).

\section{Secondary Outcomes: Clinical.}

There are several studies that shows positive effect of incretins (Glucagon like peptide, GLP-1) and incretin receptor agonist (GLP1 receptor agonists) on cardiovascular risk factors in Type 2 Diabetes (3537 ), even in patients with chronic heart failure and left ventricular dysfunction who do not have diabetes(38,39) . DPP-4 inhibitors may have cardio-protective effects of their own, as they increase bioavailability of endogenous GLP-1. They improve blood flow and Nitrous Oxide bio-availability in endothelium. These are unique properties not demonstrated by other oral diabetic medications (38-39) . The mechanism underlying these hemodynamic changes may be mediated by increased nitric oxide bioavailability but is not completely known. However, these beneficial effects may appear to be independent of glycemic reduction.

All subjects were on a stable dose of metformin (1-2 grams/day) or insulin for at least 3 months or greater. Actigraph energy monitor data analysis showed there was no difference in the average intensity of daily activity between the treatment and placebo groups. This indicated that no changes in any outcome measures in the linagliptin group can be attributed to just exercise. There are also few studies that show the effect of metformin on endogenous $\operatorname{GLP} 1(40,41)$. These pose the possibility of a limit to the effect of DPP-4 inhibitors and Incretin analogues on patients with concurrent metformin. More studies are needed, possibly on patients without metformin to clarify these effects. These also might explain the modest effect we noticed in this study and our last study with Saxagliptin.

Arterial stiffness is a measure of compliance and contractility of one's arteries, and their ability to constrict and dilate in response to changes in blood pressure. It is measured non-invasively by assessing pulse wave velocity (PWV) and pulse wave analysis (PWA) and has been noted to increase naturally with age. 
PWV is measured as a velocity in $\mathrm{m} / \mathrm{s}$. Higher values of augmentation pressure (AP), augmentation index (Al), Al-75, and PWV are correlated to higher levels of arterial stiffness. PWV, in addition to PWA measures such as blood pressure and Al, have been found to be a predictor of increased CVD risk in the general population, and especially in those at an increased risk, such as patients with T2DM. Arterial stiffness, being a direct measure of the radial, carotid and femoral arteries, would be expected to change with significant alterations to the endothelium(19,42,43) .

There was statistically significant difference noted in Augmentation Index-75, a measure of arterial stiffness, between the treatment and placebo group. There was no significant effect of treatment group $(p=0.07)$, or of time $(p=0.98)$, but there was a significant group $x$ time interaction $(p=0.02)$. The Linagliptin group showed improved parameters of arterial stiffness compared to the placebo group if all data from visit 1 to visit 2 and visit 3 are considered (Figure 6B). Interesting pattern can also be appreciated in figure $6 \mathrm{~A}$, of Pulse Wave Velocity, another measure of arterial stiffness. At Visit 1, the linagliptin group had lower $P W V$ at a trend level of significance $(p=.06)$. At visit 2 , there was no difference $(p=.91)$. At visit 3 , the linagliptin group had significantly lower PWV $(p=.03)$. The Linagliptin group showed increased PWV from visit 1 to visit 2, however decreased significantly more from visit 2 to 3 , compared to the control group. Our study shows a reduction in arterial stiffness in the Linagliptin group, as seen through a reduction in Al-75. This was also seen with other DPP-4 inhibitors, sitagliptin and vildagliptin, which resulted in a reduction in Al-75(44,45). Arterial Stiffness, as measured via Al-75 is a strong predictor of CVD in Type 2 Diabetes(45-47) . The reduction in Al-75 may be attributed to a multi-platform effect. DPP-4 inhibitors cause an increase in systemic incretin levels, which can cause a relaxation of the arteries via nitric oxide (NO)(45) - This could be attributed to a reduction in arterial stiffness. Also, the higher percentage of CD34+ve CXCR4 receptor +ve cells that was reported in our cellular analysis may indicate that EPCs are having a regenerative effect on the subjects' arteries across the 12-week time-period.

In the Saxagliptin study we conducted, did not have arterial stiffness improvement (particularly PWV) as robustly as Linagliptin, despite this cohort being sicker with both T2DM and CKD. This is corroborated by de Boer et al which had similar result with 26 weeks of treatment with Linagliptin(46). Therefore, Linagliptin appears to have clinically relevant and important arterial stiffness reduction capability even more so another similar compound (saxagliptin) within the same class of medications (DPP4 enzyme inhibitors)

Finally, DPP-4 inhibitors help patients achieve a better level of glycemic control noted even a relatively short period of intervention of 12 weeks.

There also was no change in waist or hip circumference measurements, which is consistent with other studies involving linagliptin and saxagliptin, although these studies did not have concomitant metformin therapy(46). These parameters usually takes longer to show a response within a short period of 12 week duration which maybe too short to demonstrate bio-physical changes. Previous studies have shown involving mice have shown that treatment with DPP-4 inhibitors in hyperglycemic obese mice resulted in reduction in adiposity, both in body fat percentage and abdominal fat mass(44). This was attributed to 
an increase in energy expenditure, which was measured via monitoring metabolic rate and food intake. The difference in change in weight between the treatment and placebo group was not statistically significant, alongside Resting Energy Expenditure.

Study such as CARMELINA was done on a similar cohort(48), with T2DM and CKD, randomized to either $5 \mathrm{mg}$ Linagliptin or placebo added to standard baseline treatment. That study was endpoint driven and Linagliptin was found to be noninferior to placebo plus standard treatment. Based on our results, the positive CVD outcome for CARMELINA, may be attributed to better chemotaxis of CD34+ve cells and improvement in arterial stiffness

Previous studies investigating DPP-4 inhibitor therapy mainly sitagliptin and vildagliptin, in a type 2 diabetes population found that there was no significant reduction in $\mathrm{HbA1c}$ values with treatment(45) . An interesting pattern can be appreciated in Figure 5 ( $\mathrm{HbA} 1 \mathrm{c})$. The strongest effect of all the variable is the effect on time on $\mathrm{HbA1c}(\mathrm{p}<0.005)$, which means $\mathrm{HbA} 1 \mathrm{c}$ went down substantially in both the treatment and control group. Even though the effect of treatment on this variable was not significant, after the effect of time was accounted for, interesting trend pattern can be appreciated when it's graphed. The $\mathrm{Hba} 1 \mathrm{c}$ is relatively stable in the placebo group but has a clear downward trend in the treatment group. We found statistically significant difference in the LDL over HDL ratio $(p<0.04)$. Lower the number, better the clinical outcome because higher ratio means a combination of increasing LDL and decreasing HDL, both of which correlates with adverse clinical outcome. A better profile of LDL:HDL ratio may corroborate with the ability of Linagliptin to improve cardiovascular risk profile.

As one of the main inclusion criteria of this study was subjects with CKD, all the data were stratified between CKD with normal GFR (Stage I) and CKD with reduced GFR (Stage II and below, or GFR < 60). There was no difference in effect of the treatment on the parameters that was studied. When Microalbumin over Creatine ratio was graphed (Figure 4), it can be appreciated that proteinuria has remained steady in placebo group whilst in Linagliptin group there was a transient rise followed by a drop with higher slope or gradient, compared to the placebo group. This relationship was not statistically significant.

To discern the effect of linagliptin on kidneys and particularly podocyte health, we also looked at three urinary exosome proteins, such as Podocalxyin, Wilm's tumor and Nephrin. These levels were compared to CD-9 and Alix, two exosome markers. Though our results did not give a statistical difference it clearly showed a trend of improvement in the levels of the urinary exosomal proteins in this T2DM+CKD population. We believe urinary exosomes could be an important clinical modality to discern podocyte health.

Overall, we believe that cellular parameter such CD34+ progenitor cell study along with clinically relevant parameters such as arterial stiffness helps to evaluate a diabetes medication quite thoroughly. Based on our studies using exercise physiology, saxagliptin and linagliptin as interventions we believe along with few other investigators (9) that circulating endothelial progenitor cells can help assess and possibly predict future risk of adverse cardiovascular morbidity and mortality. Our study indicates certain positive 
aspects of linagliptin, compared to saxagliptin, such as increased CD34/CD184 cell numbers, lesser PWV, improved $\mathrm{HbA} 1 \mathrm{C}$ and positive antioxidant gene expressions in blood derived cells

\section{Limitations of our study}

Limitations of our study may include the relatively short duration of 12-week Linagliptin therapy, which may have been inadequate to see significant changes in certain clinical and cellular parameters. This may have been because of the small sample size, and due to the difficulty in obtaining all cellular outcome measures, in some patients, due to low total CD34+ cell numbers. Further studies with a larger population and longer duration may be helpful to further define the mechanisms behind our findings.

\subsection{Conclusion}

It could be concluded that when Linagliptin when added to subjects with Type 2 Diabetes and Chronic Kidney Disease, along with metformin and/or Insulin, demonstrates a functional improvement of CD34 + Endothelial Progenitor Cell migratory function through increased CD34/CXCR4 positivity. We have also observed concomitant improvement in Arterial stiffness parameters along with improvement in lipid profile and $\mathrm{HbA} 1 \mathrm{C}$.

We believe CD34 + cells can act as a valuable biomarker for assessment of endothelial function, in a setting of diabetes and can help provide valuable clinical information leading to appropriate therapeutic intervention choices.

\section{Abbreviations}

Al - Augmentation Index

Al-75 - Augmentation Index adjusted for a heart rate of 75

AP - Augmentation Pressure

AS - Arterial stiffness

BCl-2 - B-cell lymphoma 2

BMI - Body mass index

BUN - Blood urea nitrogen

CASP-3 - Caspase 3

CAT -- Catalase

CDKN1 A - cyclin-dependent kinase inhibitor $1 \mathrm{~A}$ 
CD34 - Progenitor marker

CFU - Colony forming units

CVD - Cardiovascular disease

CXCR4 - C-X-C Motif Chemokine Receptor 4

DBP - Diastolic blood pressure

DPP-4 Inhibitors - Dipeptidyl peptidase-4 inhibitors

EDN-1 - Endothelin 1

eGFR - Estimated glomerular filtration rate

ELISA - Enzyme-Linked Immunosorbent Assay

eNOS - Nitric Oxide Synthase 3 (Endothelial Cell)

EPCs - Endothelial Progenitor Cells

FFM - Fat free mass

GAPDH - Glyceraldehyde-3-Phosphate Dehydrogenase

GLP1 - Glucagon Like Peptide 1

GPX1 - Glutathione Peroxidase 1

HbA1C - Hemoglobin A1C, glycated hemoglobin test

IGF1 - Insulin-like growth factor 1

IL-6 - Interleukin 6

$\mathrm{kg}$ - Kilograms (weight)

lbs - Pounds (weight)

MNCs - Mononuclear cells

PECAM1 - Platelet And Endothelial Cell Adhesion Molecule 1

PWA - Pulse Wave Analysis

PWV - Pulse Wave Velocity 
qRT-PCR - Quantitative reverse transcriptase polymerase chain reaction

REE - resting energy expenditure

SBP - Systolic blood pressure

SDF1a - Stromal cell-derived factor-1a

SOD1, SOD2 - Super oxide dismutase $1 \& 2$

TBW - Total body water

TNFa - Tumor Necrosis Factor a

TP53 - Tumor protein p53

VEGF - vascular endothelial growth factor

VEGFA - Vascular Endothelial Growth Factor A

VEGFR2 - Vascular endothelial growth factor receptor 2

VO2 - Maximal oxygen consumption

18S - 18Sribosomal RNA

\section{Declarations}

Study registered at ClinicalTrials.gov Identifier: NCT02467478

Ethics approval and consent to participate: Our study was approved by the George Washington University Institutional Review Board and was conducted in accordance with Good Clinical Practices of the National Institutes of Health. Signed informed consent was obtained by all subjects prior to engaging in any research.

Consent for publications: Not applicable

Availability of data and material: All associated data will be available to the public, as requested.

Demography of subjects including detailed description of baseline characteristics and parameters have been included in the Appendices

Competing interests: The authors declare that they have no competing interests

Funding: Boerhinger Ingelheim, Inc.

Author's contributions: 
HA as first author performed the experiments and were responsible for collection and compilation of data, analysis of data, and in writing the manuscript

SRN compiled and helped analyze particularly CD negative cells. He also contributed to the methods and results section

CCD performed all the cellular experiments and analysis.

FJD has collected clinical assessments

NK contributed to cellular outcomes, and aided in editing the manuscript for publication

BB conducted the urine exosome based assay, including related data compilation and analysis

NA, SS and AE contributed in performing cellular experiments and gene expression.

MF has contributed in the collection and complication of clinical data.

RA performed the statistical analyses of the data set, and SS designed and supervised the study and revised the manuscript. All authors read and approved the final manuscript.

Acknowledgement: Not Applicable

The author(s) meet criteria for authorship as recommended by the International Committee of Medical Journal Editors (ICMJE). This study was supported by Boehringer Ingelheim Pharmaceuticals, Inc. (BIPI). $B I P I$ had no role in the design, analysis or interpretation of the results in this study; BIPI was given the opportunity to review the manuscript for medical and scientific accuracy as it relates to BIPI substances, as well as intellectual property considerations

\section{References}

(1) Estimates of Diabetes, Its Burden in the United States. National Diabetes Statistics Report, 2017. Department of Health and Human Services, NIH, 2008 and National Center for Chronic Disease Prevention and Health Promotion, 20112017.

(2) Standards of Medical Care in Diabetes-2014. Diabetes care 2014 Jan;37 Suppl 1(1):S14-S80.

(3) Afkarian M, Sachs MC, Kestenbaum B, Hirsch IB, Tuttle KR, Himmelfarb J, et al. Kidney disease and increased mortality risk in type 2 diabetes. J Am Soc Nephrol 2013 February 01;24(2):302-308.

(4) Sheetz MJ, King GL. Molecular understanding of hyperglycemia's adverse effects for diabetic complications. JAMA 2002 November 27;288(20):2579-2588.

(5) Rask-Madsen C, King GL. Mechanisms of Disease: endothelial dysfunction in insulin resistance and diabetes. Nat Clin Pract Endocrinol Metab 2007 January 01;3(1):46-56. 
(6) Hill JM, Zalos G, Halcox JP, Schenke WH, Waclawiw MA, Quyyumi AA, et al. Circulating endothelial progenitor cells, vascular function, and cardiovascular risk. N Engl J Med 2003 February 13;348(7):593600 .

(7) Krenning G, Dankers PY, Drouven JW, Waanders F, Franssen CF, van Luyn MJ, et al. Endothelial progenitor cell dysfunction in patients with progressive chronic kidney disease. Am J Physiol Renal Physiol 2009 June 01;296(6):1314.

(8) Tepper OM, Galiano RD, Capla JM, Kalka C, Gagne PJ, Jacobowitz GR, et al. Human endothelial progenitor cells from type II diabetics exhibit impaired proliferation, adhesion, and incorporation into vascular structures. Circulation 2002 November 26;106(22):2781-2786.

(9) Werner N, Wassmann S, Ahlers P, Kosiol S, Nickenig G. Circulating CD31+/annexin V+ apoptotic microparticles correlate with coronary endothelial function in patients with coronary artery disease. Arterioscler Thromb Vasc Biol 2006 January 01;26(1):112-116.

(10) Kundu N, Domingues CC, Chou C, Ahmadi N, Houston S, Jerry DJ, et al. Use of p53-Silenced Endothelial Progenitor Cells to Treat Ischemia in Diabetic Peripheral Vascular Disease. J Am Heart Assoc 2017 April 01;6(4):10.1161/JAHA.116.005146.

(11) Caballero S, Sengupta N, Afzal A, Chang KH, Li Calzi S, Guberski DL, et al. Ischemic vascular damage can be repaired by healthy, but not diabetic, endothelial progenitor cells. Diabetes 2007 April 01;56(4):960967.

(12) Ridker PM, Danielson E, Fonseca FAH, Genest J, Gotto AM, Kastelein JJP, et al. Rosuvastatin to Prevent Vascular Events in Men and Women with Elevated C-Reactive Protein. N Engl J Med 2008;359(21):2195-2207.

(13) Fadini GP, Boscaro E, Albiero M, Menegazzo L, Frison V, de Kreutzenberg S, et al. The oral dipeptidyl peptidase-4 inhibitor sitagliptin increases circulating endothelial progenitor cells in patients with type 2 diabetes: possible role of stromal-derived factor-1alpha. Diabetes Care 2010 July 01;33(7):1607-1609.

(14) Huang CY, Shih CM, Tsao NW, Lin YW, Huang PH, Wu SC, et al. Dipeptidyl peptidase-4 inhibitor improves neovascularization by increasing circulating endothelial progenitor cells. Br J Pharmacol 2012 December 01;167(7):1506-1519.

(15) Losordo DW, Schatz RA, White CJ, Udelson JE, Veereshwarayya V, Durgin M, et al. Intramyocardial transplantation of autologous CD34+ stem cells for intractable angina: a phase I/lla double-blind, randomized controlled trial. Circulation 2007 June 26;115(25):3165-3172.

(16) Marrotte EJ, Chen DD, Hakim JS, Chen AF. Manganese superoxide dismutase expression in endothelial progenitor cells accelerates wound healing in diabetic mice. J Clin Invest 2010 December 01;120(12):4207-4219. 
(17) Losordo DW, Henry TD, Davidson C, Sup Lee J, Costa MA, Bass T, et al. Intramyocardial, autologous CD34+ cell therapy for refractory angina. Circ Res 2011 August 05;109(4):428-436.

(18) Dicker D. DPP-4 inhibitors: impact on glycemic control and cardiovascular risk factors. Diabetes Care 2011 May 01;34 Suppl 2:276.

(19) Li F, Chen J, Leng F, Lu Z, Ling Y. Effect of Saxagliptin on Circulating Endothelial Progenitor Cells and Endothelial Function in Newly Diagnosed Type 2 Diabetic Patients. Exp Clin Endocrinol Diabetes 2017 June 01;125(6):400-407.

(20) Fadini GP, Bonora BM, Cappellari R, Menegazzo L, Vedovato M, lori E, et al. Acute Effects of Linagliptin on Progenitor Cells, Monocyte Phenotypes, and Soluble Mediators in Type 2 Diabetes. J Clin Endocrinol Metab 2016 February 01;101(2):748-756.

(21) Herrera C, Morimoto C, Blanco J, Mallol J, Arenzana F, Lluis C, et al. Comodulation of CXCR4 and CD26 in Human Lymphocytes. J Biol Chem 2001 06/01/;276(22):19532-19539.

(22) Zheng H, Fu G, Dai T, Huang H. Migration of endothelial progenitor cells mediated by stromal cellderived factor-1alpha/CXCR4 via PI3K/Akt/eNOS signal transduction pathway. J Cardiovasc Pharmacol 2007 September 01;50(3):274-280.

(23) Yin Y, Zhao X, Fang Y, Yu S, Zhao J, Song M, et al. SDF-1a involved in mobilization and recruitment of endothelial progenitor cells after arterial injury in mice. Cardiovascular Pathology 2010;19(4):218-227.

(24) Moore MA, Hattori K, Heissig B, Shieh JH, Dias S, Crystal RG, et al. Mobilization of endothelial and hematopoietic stem and progenitor cells by adenovector-mediated elevation of serum levels of SDF-1, VEGF, and angiopoietin-1. Ann N Y Acad Sci Invalid date Invalid date;938:36-7.

(25) American Diabetes Association. Pharmacologic Approaches to Glycemic Treatment. Diabetes Care 2017;40:S64-S74.

(26) Kirpichnikov D, McFarlane SI, Sowers JR. Metformin: an update. Ann Intern Med 2002 July 02;137(1):25-33.

(27) Effect of intensive blood-glucose control with metformin on complications in overweight patients with type 2 diabetes (UKPDS 34). UK Prospective Diabetes Study (UKPDS) Group. Lancet 1998 September 12;352(9131):854-865.

(28) Fung CS, Wan EY, Wong CK, Jiao F, Chan AK. Effect of metformin monotherapy on cardiovascular diseases and mortality: a retrospective cohort study on Chinese type 2 diabetes mellitus patients. Cardiovasc Diabetol 2015 October 09;14:137-2.

(29) Ahmed FW, Rider R, Glanville M, Narayanan K, Razvi S, Weaver JU. Metformin improves circulating endothelial cells and endothelial progenitor cells in type 1 diabetes: MERIT study. Cardiovasc Diabetol 
(30) Quinn U, Tomlinson LA, Cockcroft JR. Arterial stiffness. JRSM Cardiovasc Dis 2012 September 30;1(6):10.1258/cvd.2012.012024.

(31) Stoner L, Young JM, Fryer S. Assessments of arterial stiffness and endothelial function using pulse wave analysis. Int J Vasc Med 2012;2012:903107.

(32) Sen, S., Witkowski, S., Lagoy, A., Islam,A. A Six-Week Home Exercise Program Improves Endothelial Function and CD34+ Circulating Progenitor Cells in Patients With Pre-Diabetes. Journal of Endocrinology and Metabolism 2015;5(1-2).

(33) Dore FJ, Domingues CC, Ahmadi N, Kundu N, Kropotova Y, Houston S, et al. The synergistic effects of saxagliptin and metformin on CD34+ endothelial progenitor cells in early type 2 diabetes patients: a randomized clinical trial. Cardiovasc Diabetol 2018 May 03;17(1):65-9.

(34) Jarajapu YP, Caballero S, Verma A, Nakagawa T, Lo MC, Li Q, et al. Blockade of NADPH oxidase restores vasoreparative function in diabetic CD34+ cells. Invest Ophthalmol Vis Sci 2011 July 07;52(8):5093-5104.

(35) Verge D, Lopez X. Impact of GLP-1 and GLP-1 receptor agonists on cardiovascular risk factors in type 2 diabetes. Curr Diabetes Rev 2010 July 01;6(4):191-200.

(36) Marso SP, Bain SC, Consoli A, Eliaschewitz FG, Jodar E, Leiter LA, et al. Semaglutide and Cardiovascular Outcomes in Patients with Type 2 Diabetes. N Engl J Med 2016 November 10;375(19):1834-1844.

(37) Marso SP, Daniels GH, Brown-Frandsen K, Kristensen P, Mann JF, Nauck MA, et al. Liraglutide and Cardiovascular Outcomes in Type 2 Diabetes. N Engl J Med 2016 July 28;375(4):311-322.

(38) Sokos GG, Nikolaidis LA, Mankad S, Elahi D, Shannon RP. Glucagon-like peptide-1 infusion improves left ventricular ejection fraction and functional status in patients with chronic heart failure. $\mathrm{J}$ Card Fail 2006 December 01;12(9):694-699.

(39) Nikolaidis LA, Mankad S, Sokos GG, Miske G, Shah A, Elahi D, et al. Effects of glucagon-like peptide-1 in patients with acute myocardial infarction and left ventricular dysfunction after successful reperfusion. Circulation 2004 March 02;109(8):962-965.

(40) Wu T, Thazhath SS, Bound MJ, Jones KL, Horowitz M, Rayner CK. Mechanism of increase in plasma intact GLP-1 by metformin in type 2 diabetes: stimulation of GLP-1 secretion or reduction in plasma DPP4 activity? Diabetes Res Clin Pract 2014 October 01;106(1):3.

(41) Mannucci E, Ognibene A, Cremasco F, Bardini G, Mencucci A, Pierazzuoli E, et al. Effect of metformin on glucagon-like peptide 1 (GLP-1) and leptin levels in obese nondiabetic subjects. Diabetes Care 2001 
March 01;24(3):489-494.

(42) Muniyappa R, lantorno M, Quon MJ. An integrated view of insulin resistance and endothelial dysfunction. Endocrinol Metab Clin North Am 2008 September 01;37(3):685-x.

(43) Lovshin JA, Drucker DJ. Incretin-based therapies for type 2 diabetes mellitus. Nat Rev Endocrinol 2009 May 01;5(5):262-269.

(44) Goldsmith F, Keenan MJ, Raggio AM, Ye X, Hao Z, Durham H, et al. Induction of Energy Expenditure by Sitagliptin Is Dependent on GLP-1 Receptor. PLoS One 2015 May 04;10(5):e0126177.

(45) Duvnjak L, Blaslov K. Dipeptidyl peptidase-4 inhibitors improve arterial stiffness, blood pressure, lipid profile and inflammation parameters in patients with type 2 diabetes mellitus. Diabetol Metab Syndr 2016 March 22;8:26-6. eCollection 2016.

(46) de Boer SA, Heerspink HJL, Juárez Orozco LE, van Roon AM, Kamphuisen PW, Smit AJ, et al. Effect of linagliptin on pulse wave velocity in early type 2 diabetes: A randomized, double-blind, controlled 26week trial (RELEASE). Diabetes Obes Metab 2017;19(8):1147-1154.

(47) Cecelja M, Chowienczyk P. Role of arterial stiffness in cardiovascular disease. JRSM Cardiovasc Dis 2012 July 31;1(4):10.1258/cvd.2012.012016.

(48) Rosenstock J, Perkovic V, Johansen OE, Cooper ME, Kahn SE, Marx N, et al. Effect of Linagliptin vs Placebo on Major Cardiovascular Events in Adults With Type 2 Diabetes and High Cardiovascular and Renal Risk: The CARMELINA Randomized Clinical Trial. JAMA 2019;321(1):69-79.

\section{Tables}

\section{Table 1 Baseline Characteristics and Demographics}




\begin{tabular}{|c|c|c|c|}
\hline Variable & Placebo $(n=17)$ & Linagliptin $(n=14)$ & $\mathrm{p}$ \\
\hline Age (years), mean \pm SD & $63 \pm 6$ & $61 \pm 5$ & .21 \\
\hline Sex female, n\% & $10(59 \%)$ & $3(21 \%)$ & .04 \\
\hline Race & & & .49 \\
\hline BL & $12(71 \%)$ & $8(57 \%)$ & \\
\hline Wh & $4(24 \%)$ & $3(21 \%)$ & \\
\hline Other & $1(6 \%)$ & $3(21 \%)$ & \\
\hline \multicolumn{4}{|l|}{ Medications: } \\
\hline Metformin & $14(82 \%)$ & $12(86 \%)$ & .99 \\
\hline Insulin & $6(35 \%)$ & $5(36 \%)$ & .99 \\
\hline \multicolumn{4}{|l|}{ BP } \\
\hline Systolic & $133 \pm 18$ & $128 \pm 10$ & .30 \\
\hline Diastolic & $77 \pm 7$ & $81 \pm 7$ & .23 \\
\hline BMI & $30.6 \pm 2.9$ & $31.2 \pm 4.4$ & .67 \\
\hline Percent fat & $38 \pm 10$ & $30 \pm 10$ & .04 \\
\hline Waist cm & $105 \pm 8$ & $107 \pm 17$ & .22 \\
\hline Basic Metabolic Rate & $1476 \pm 448$ & $1868 \pm 293$ & .02 \\
\hline Fasting Glucose & $130 \pm 44$ & $125 \pm 26$ & .70 \\
\hline Serum creatinine & $0.9 \pm 0.3$ & $1.1 \pm 0.4$ & .24 \\
\hline eGFR & $84 \pm 19$ & $83 \pm 21$ & .85 \\
\hline Cholesterol & $168 \pm 53$ & $166 \pm 52$ & .92 \\
\hline HbA1c & $7.4 \pm 1.0$ & $7.1 \pm 0.7$ & .50 \\
\hline
\end{tabular}

Table 2: Blood biochemistry before and after Linagliptin treatment. 


\begin{tabular}{|c|c|c|c|c|}
\hline & Visit 1 & Visit 2 & Visit 3 & p-value \\
\hline Glucose & & & & 0.47 \\
\hline Placebo & $129.88 \pm 43.78$ & $129.35 \pm 41.39$ & $129.65 \pm 46.78$ & \\
\hline Linagliptin & $124.71 \pm 25.94$ & $116.15 \pm 23.16$ & $109.92 \pm 16.81$ & \\
\hline BUN & & & & 0.07 \\
\hline Placebo & $16.00 \pm 5.56$ & $17.41 \pm 5.98$ & $16.76 \pm 5.85$ & \\
\hline Linagliptin & $18.07 \pm 7.33$ & $16.08 \pm 6.10$ & $16.85 \pm 6.41$ & \\
\hline Serum Creatinine & & & & 0.59 \\
\hline Placebo & $0.93 \pm 0.27$ & $0.91 \pm 0.24$ & $0.92 \pm 0.25$ & \\
\hline Linagliptin & $1.06 \pm 0.35$ & $1.08 \pm 0.43$ & $1.1 \pm 0.38$ & \\
\hline eGFR & & & & 0.78 \\
\hline Placebo & $84.06 \pm 19.41$ & $85.88 \pm 19.41$ & $84.12 \pm 19.81$ & \\
\hline Linagliptin & $82.71 \pm 20.96$ & $82.85 \pm 22.38$ & $79.46 \pm 19.9$ & \\
\hline Cholesterol & & & & 0.14 \\
\hline Placebo & $168.12 \pm 53.16$ & $173.29 \pm 40.41$ & $171.65 \pm 48.49$ & \\
\hline Linagliptin & $166.29 \pm 51.63$ & $154.46 \pm 37.32$ & $159.69 \pm 48.53$ & \\
\hline Triglycerides & & & & 0.13 \\
\hline Placebo & $118 \pm 81.86$ & $143.47 \pm 126.7$ & $127.76 \pm 79.04$ & \\
\hline Linagliptin & $133.43 \pm 67.97$ & $130 \pm 58.64$ & $124.31 \pm 50.67$ & \\
\hline LDL/HDL & & & & 0.04 \\
\hline Placebo & $1.76 \pm 1.00$ & $1.82 \pm 0.83$ & $1.76 \pm 0.89$ & \\
\hline Linagliptin & $1.83 \pm 0.78$ & $1.65 \pm 0.7$ & $1.92 \pm 0.87$ & \\
\hline HbA1c & & & & 0.12 \\
\hline Placebo & $7.35 \pm 0.97$ & $7.10 \pm 0.79$ & $7.27 \pm 0.73$ & \\
\hline Linagliptin & $7.14 \pm 0.67$ & $6.76 \pm 0.44$ & $6.66 \pm 0.40$ & \\
\hline C-Reactive Protein & & & & 0.49 \\
\hline Placebo & $4.50 \pm 9.73$ & $2.77 \pm 2.51$ & $3.08 \pm 3.41$ & \\
\hline Linagliptin & $13.53 \pm 31.32$ & $8.4 \pm 16.03$ & $5.17 \pm 6.54$ & \\
\hline IL6 & & & & 0.18 \\
\hline
\end{tabular}




\begin{tabular}{|lllll|}
\hline Placebo & $5.16 \pm 10.71$ & $2.72 \pm 3.01$ & $2.18 \pm 1.45$ & \\
\hline TNFa & $6.42 \pm 11.00$ & $5.24 \pm 7.39$ & $5.09 \pm 6.08$ & \\
\hline Placebo & & & & \\
\hline Linagliptin & $4.01 \pm 10.42$ & $5.94 \pm 12.13$ & $1.77 \pm 1.94$ & \\
\hline Leptin & & $2.25 \pm 2.57$ & $1.92 \pm 1.52$ & \\
\hline Placebo & $22.48 \pm 12.6$ & $54.08 \pm 130.71$ & $22.88 \pm 13.25$ & \\
\hline Linagliptin & $21.69 \pm 22.77$ & $23.06 \pm 25.72$ & $23.91 \pm 25.83$ & \\
\hline Adiponectin & & & & 0.98 \\
\hline Placebo & $6.57 \pm 5.04$ & $6.5 \pm 6.59$ & $6.64 \pm 6.33$ & \\
\hline Linagliptin & $5.39 \pm 3.08$ & $5.52 \pm 2.98$ & $5.45 \pm 3.28$ & \\
\hline Insulin & & & & 0.87 \\
\hline Placebo & $17.85 \pm 14.07$ & $19.84 \pm 11.83$ & $20.82 \pm 12.6$ & \\
\hline Linagliptin & $16.43 \pm 12.9$ & $16.06 \pm 8.51$ & $20.52 \pm 19.71$ & \\
\hline Uric Acid & & & & 0.97 \\
\hline Placebo & $6.51 \pm 1.57$ & $6.59 \pm 1.21$ & $6.73 \pm 1.43$ & \\
\hline Linagliptin & $5.89 \pm 1.78$ & $5.96 \pm 1.49$ & $12.52 \pm 21.85$ & \\
\hline
\end{tabular}

\section{Appendix I}

\section{Inclusion Criteria}

1. Adults aged $30-70$ years.

2. Diagnosis of type 2 diabetes within the previous 15 years using criteria of the American Diabetes Association

3. Currently treated with a stable dose of Insulin, Metformin (1-2 grams/day), or a stable combination of the two as therapy.

4. HbA1C between 6.5 to $10 \%$ (both inclusive)

5. BMI 25 to $39.9 \mathrm{~kg} / \mathrm{m} 2$ (both inclusive)

6. CKD stages 1-3

\section{Exclusion Criteria}


1. Implanted devices (e.g., pacemakers) that may interact with Tanita scale

2. Previous coronary or cerebrovascular event within 6 months of screening or active or clinically significant coronary and/or peripheral vascular disease

3. Low hematocrit (<28 UNITS).

4. Pre-existing liver disease and/or ALT and AST >2.5X's UNL

5. CKD stage 4 and

6. History of pancreatitis, or cancer (except basal cell carcinoma and cancer that is cured or not active or being treated in the past five years)

7. Statin use started or dose change in the last 3 months

8. Use of oral anti-diabetic medication other than Metformin, or Insulin.

9. Use of consistent long-term steroid medication in the last 3 months (oral, inhaled, injected).

10. Systolic BP> $140 \mathrm{mmHg}$ and Diastolic $B P>90 \mathrm{mmHg}$

11. Active wounds or recent surgery within 3 months.

12. Inflammatory disease, or chronic current use of anti-inflammatory drugs within the last 3 months

13. triglycerides $>450 \mathrm{mg} / \mathrm{dL}$

14. untreated hyper/hypothyroidism

15. Auto antibody confirmed type 1 diabetes

Additionally, patients who are active smokers, patients who are pregnant, nursing women, and postmenopausal women who are on hormone replacement therapy will be excluded.

Patients on low dose oral contraceptives will be allowed to participate as these formulations contain lesser amount of estrogens.

\section{Figures}
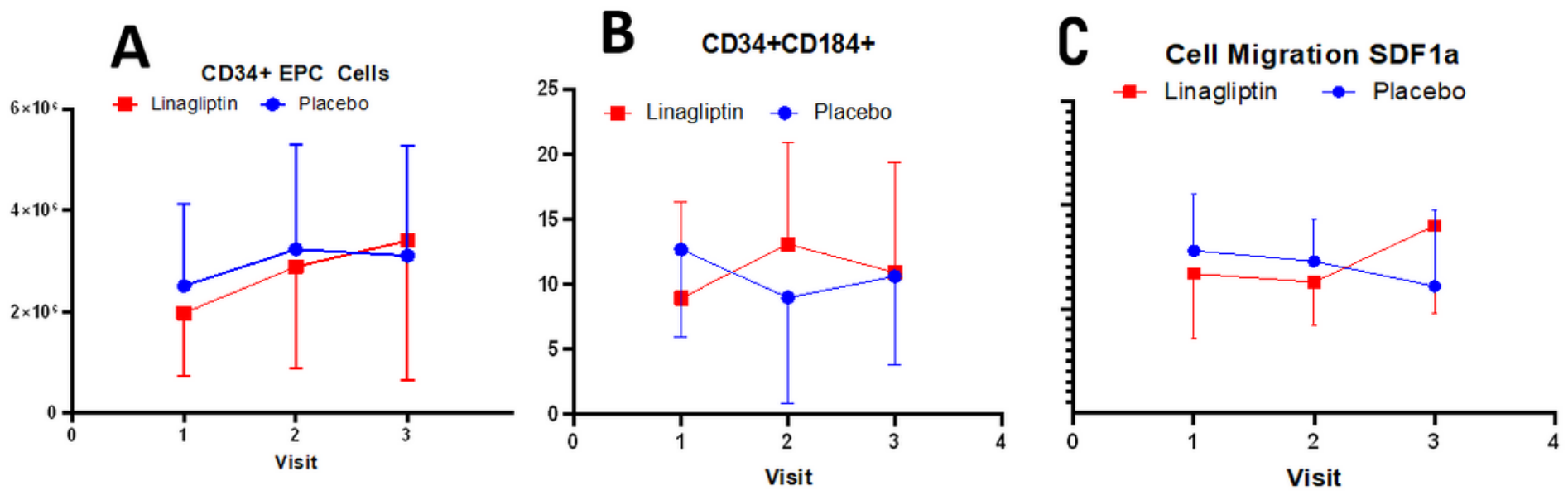

Figure 1 
Endothelial progenitor (CD34+), CD34+CD184+ cell expression and Migration. Flow cytometry-based assay for CD34positive cells and CD34+CD184 dual positive cells. A). Mean CD34 cell number increased in Linagliptin group from visit 1 to 3. B). The functional improvement of CD34+ cells can be further supported by statistically significant expression of CD34+CD184 dual positive cells (CXCR4) $(p<0.02)$ measured by flow cytometry. Interesting pattern can be appreciated here, as double positivity dropped from visit 1 to 2 in the placebo group but in Linagliptin group it went up, through the graphs merged at visit 3. C) The mean fluorescence intensities (normalized to control samples) is shown here A trend in increased migratory response of CD34+ve cells to the chemotactic factor SDF1a $(100 \mathrm{ng} / \mathrm{ml})$ is observed in linagliptin group at visit 2.

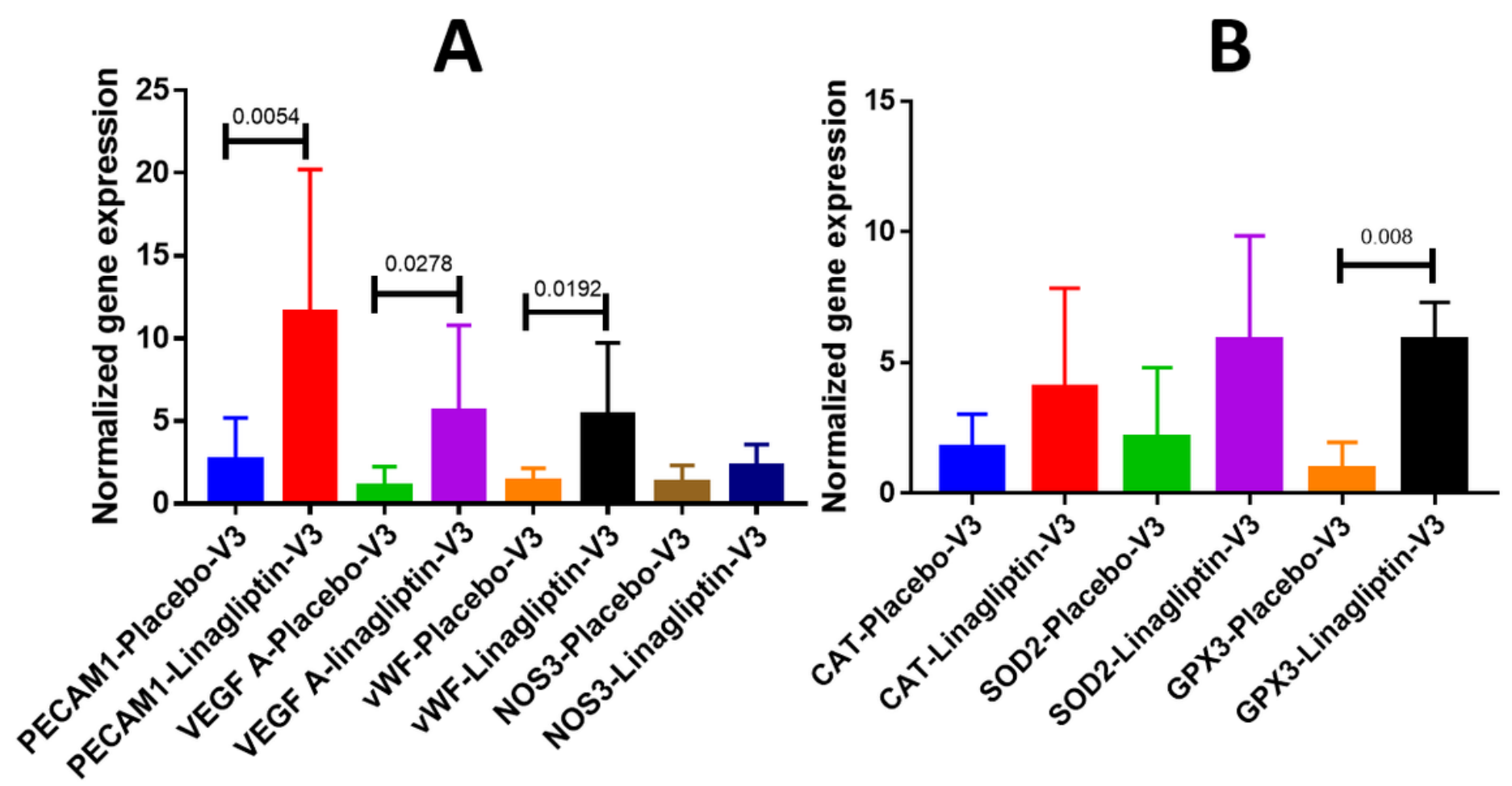

Figure 2

Gene expression of endothelial markers and antioxidant increased significantly. A. Endothelial markers PECAM1, VEGF-A and vWF gene expression on CD34 negative cells from both placebo and Linagliptin Visit 3 patients. vWF mRNA expression is predominantly increased in at Visit-3 in Linagliptin group. Gene expression is normalized with to $18 \mathrm{~S}$ and values are related to Visit-1. B. Gene expression of antioxidant markers such as Catalase(CAT), Superoxide dismutase-2 or MnSOD (SOD2) and glutathione peroxidase (GPX3) gene expression on CD34 negative cells from both placebo and Linagliptin Visit 3 patients, shown here. mRNA expressions of these genes are increased in at Visit-3 in the Linagliptin group. Gene expression is normalized to $18 \mathrm{~S}$ and gene expression values are fold difference to visit- 1 values 

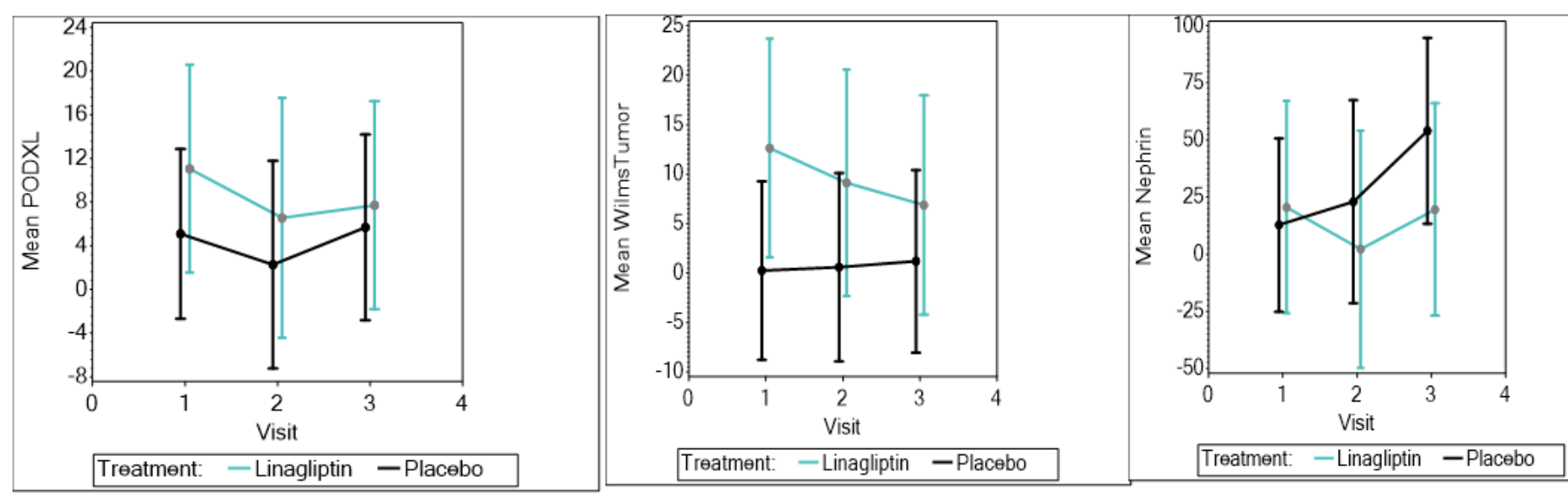

\section{Figure 3}

Urinary exosomal markers podocalxyin, Wilm's tumor and Nephrin identified by Western blot Urinary exosomal proteins noted in urine where increase in protein amount indicates worsening podocyte health were improved (or reduced) in linagliptin group in all three markers, from vist 1 to 3 whereas the trend was a flat line or increased in the placebo. Mean band intensities were represented for both placebo and Linagliptin groups from visit 1, 2, and 3. Exosomal protein CD9 was used for normalization. Line graphs for individual proteins noted in urinary exosomes are shown 


\section{MACR}

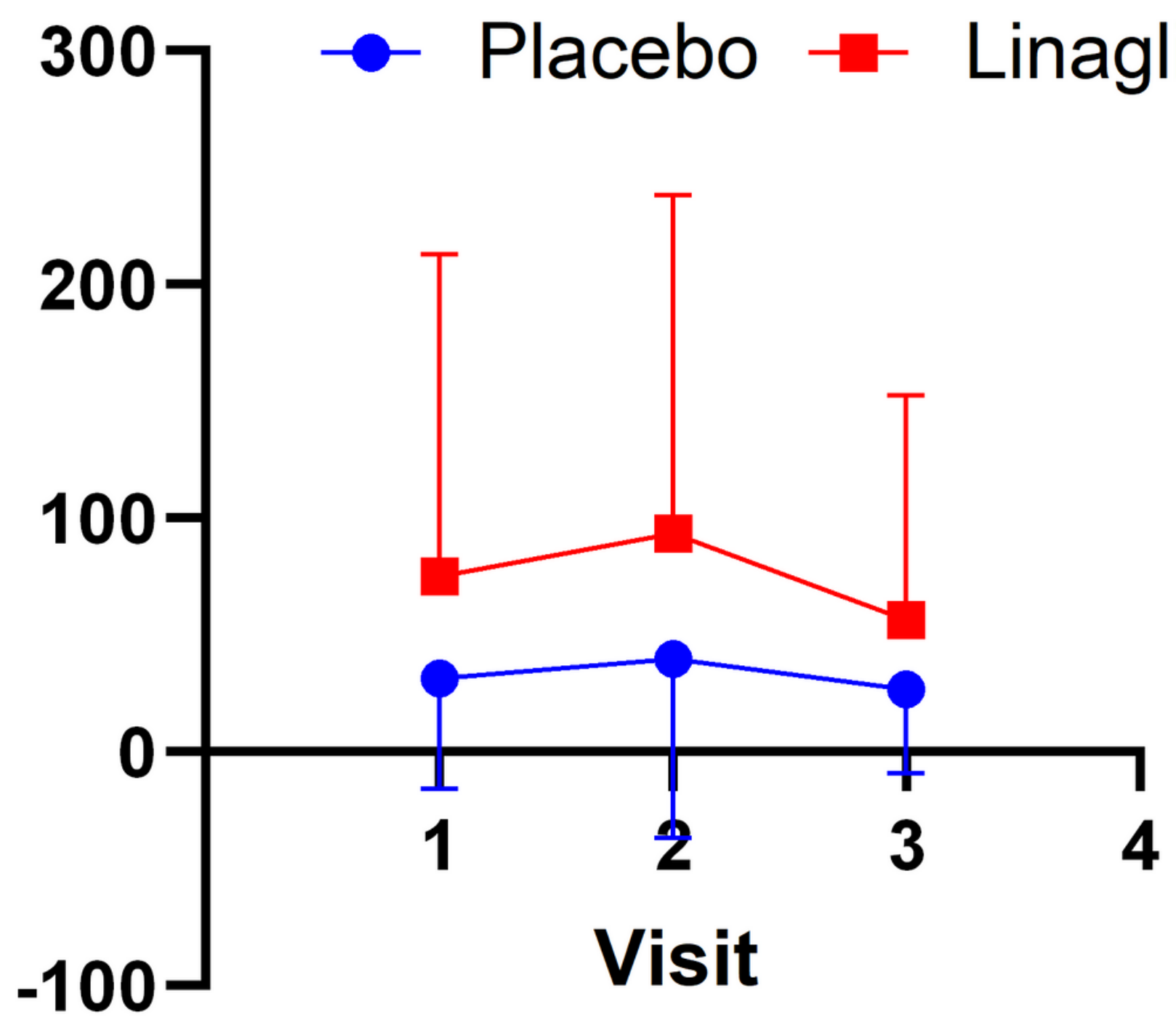

Figure 4

Microalbumin over Creatinine ratio Microalbumin: Creatinine ratio shown as line graphs over three visits. Between visit 1 and 2, the Lina and placebo line trajectories are similar, however between visit 2 and 3 , there is a sharp drop in the line trajectory particularly for Lina group. This may indicate improvement in renal function with Linagliptin, gradually over a 12-week period. This observation ( $p$ value) was not statistically significant. 


\section{HbA1c}

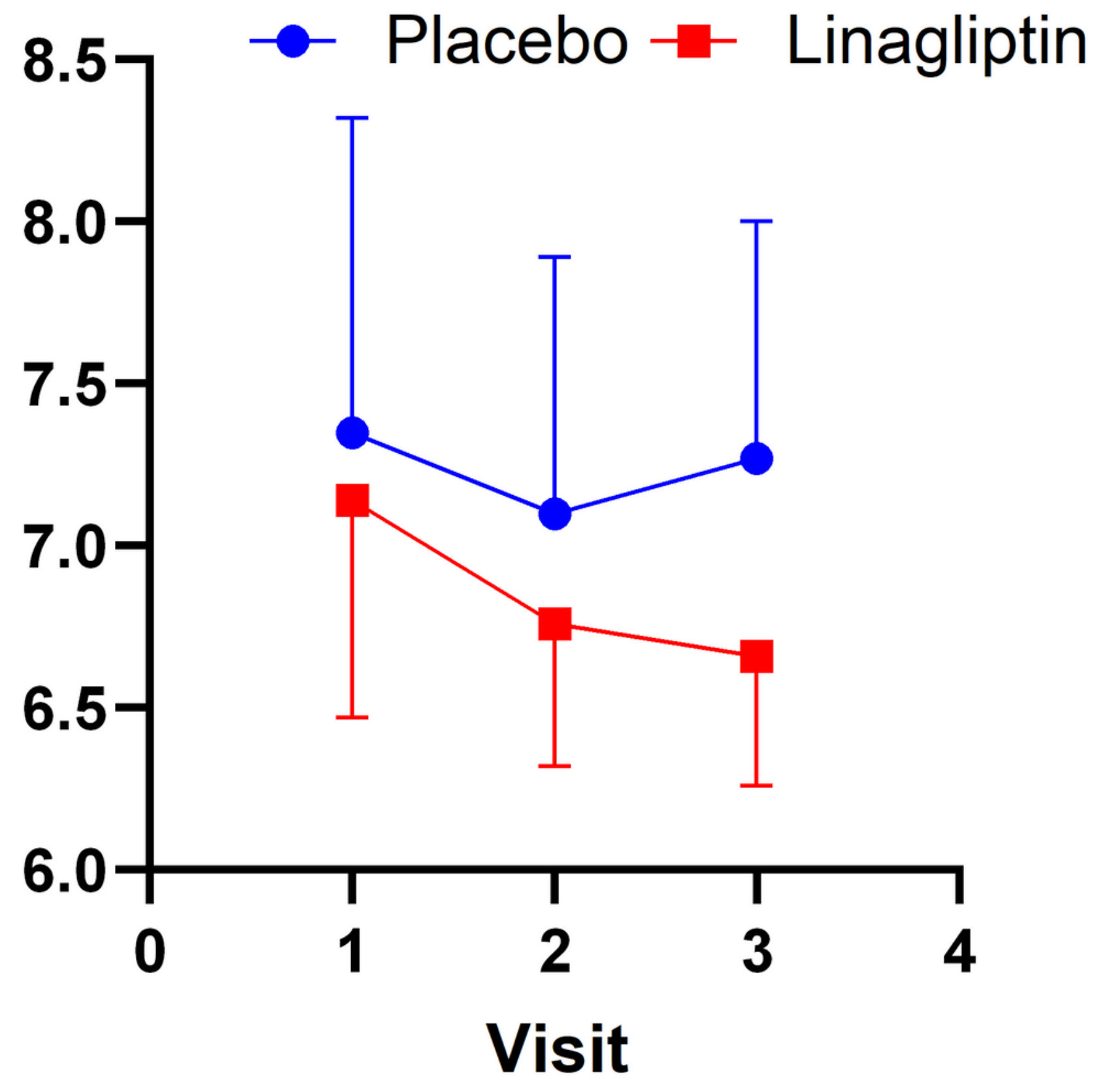

Figure 5

$\mathrm{HbA1c}$ : The strongest effect of all the variable is the effect on time on HbA1c $(p<0.005)$, which means $\mathrm{HbA1c}$ went down substantially in both the treatment and control group. Even though the effect of treatment on this variable was not significant after the effect of time was accounted for, interesting trend pattern can be appreciated when it's graphed. The Hba1c is relatively stable in the placebo group but has a clear downward trend in the treatment group. 

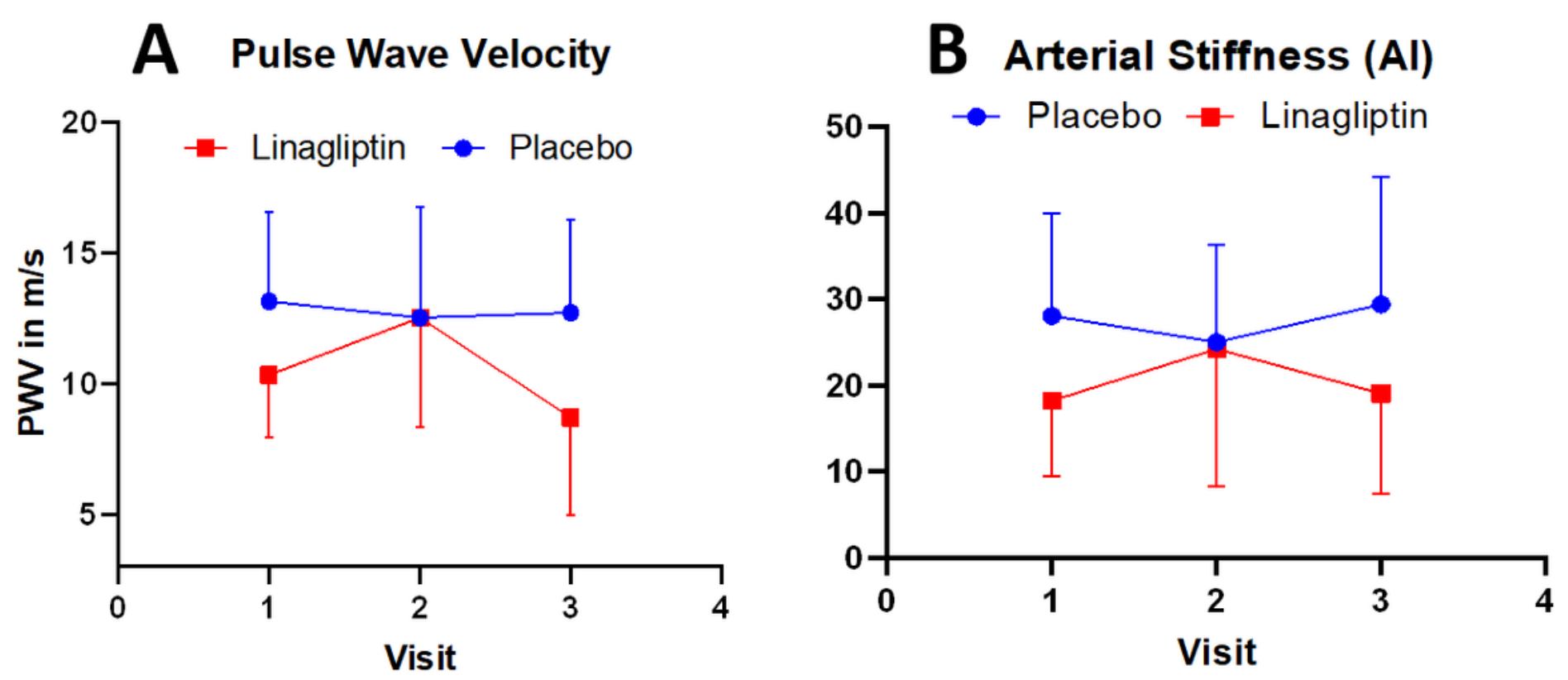

Figure 6

Arterial Stiffness Parameters A. Pulse Wave Velocity At Visit 1, the linagliptin group had lower PWV at a trend level of significance $(p=.06)$. At visit 2 , there was no difference $(p=.91)$. At visit 3 , the linagliptin group had significantly lower PWV $(p=.03)$. The Linagliptin group increased PWV more from visit 1 to visit 2, and decreased more from visit 2 to 3, compared to the control group. B. Pulse Wave Analysis A similar pattern is seen here (comparing PWV with PWA). Error bars show the $95 \%$ confidence interval for the control group. There was not a significant effect of treatment group $(p=.07)$, or of time $(p=.98)$, but there was a significant group $x$ time interaction $(p=.02)$. The Linagliptin group increased more than placebo group from visit 1 to visit 2, but then rebounded back down more than the control group at visit 3 . 